\title{
Impact of Different Objective Analyses on the Tropical Cyclone Forecast Model
}

\author{
By Xu Yiming*, \\ Shanghai Typhoon Institute, Shanghai, China \\ C. J. Neumann and A. C. Pike \\ National Hurricane Center, Coral Gables, Fla., U.S.A. \\ (Manuscript received 25 August 1986, in revised form 22 Jaunary 1987)

\begin{abstract}
We have investigted the performance of a numerical tropical cyclone forecast model over the eastern North Pacific Ocean using two different analysis schemes. These are the spectral global model analysis of the U.S. A. National Meteorological Center and the tropical numerical variational analysis of U.S. Navy Fleet Numerical Oceanography Center.

We found that the storm track forecasts using the two analyses were very different and a comparison of the prediction errors is given.
\end{abstract}

\section{Introduction}

Prior to the issuance of tropical advisories, forecast guidance from a number of statistical and numerical models are routinely provided to the hurricane forecasters at the National Hurricane Center (NHC) of U.S.A. The analysis fields for these forecast models come from U.S. A. National Meteoeological Center (NMC). A three-dimensional spectral analysis technique (Flattery, 1970) has been run at NMC from 1975 through 1984 and a series of studies into the characteristic of this spectral analysis over the tropics have already been made (Leftwich et al., 1977; Mathur, 1978; Neumann, 1979). It was found that the geopotential height analyses in tropical regions were poor and degraded the skill of the statistical models.

In order to investigate the influence of the initial analysis, a numerical tropical cyclone track model was run with two different ana-

\footnotetext{
* Research performed while on temporary assign-
} ment to the National Hurricane Center, U.S.A. lysis schemes.

\section{Analysis schemes and prediction model}

The two objective analysis used in this study are the spectral analysis of National Meteorological Center (NMC) and the numerical variational analysis of the U.S. Navy Fleet Numerical Cceanography Center (FNOC). The spectral analysis (Bergman et al., 1974) is a three dimensional global analysis and is spectral in the sense that a set of mathematical Hough function is used to describe the atmosphere. Analyzed values of the wind and pressure evaluated at latitude and longitude points. The FNOC analysis is a successive correction scheme and uses a variational principle to couple the winds and temperature in the vertical by constraining the analysis to satisfy a generalized thermal wind relationship (Fiorino, 1985).

SANBAR numerical model was used as the forecast model. It was originally developed by Sanders and Burpee (1968) and is an equivalent barotropic model which uses mass 


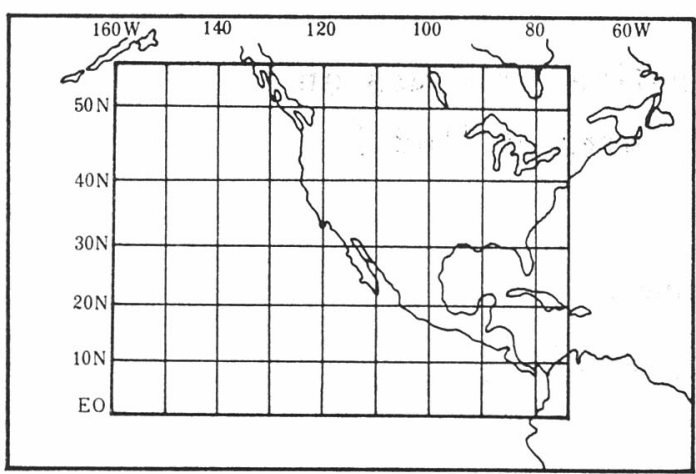

Fig. 1 The prediction domain.

weighted on vertically averaged winds from the large-scale analysis and a bogus tropical cyclone circulation. The prediction domain (see Fig. 1) is between equator and $55 \mathrm{~N}$ and longitude $73 \mathrm{~W}$ to $160 \mathrm{~W}$ on a Mercator projection grid of mesh length of $154 \mathrm{~km}$. The model has been undergone several modifications to improve its performance (Pike, 1972; Sanders, Pike and Gaertner, 1975) and we have used the most recent version.

\section{Results}

Based on two different objective analysis SANBAR was used to forecast every eastern North Pacific storm of which the maximum wind was 35 knots or greater in warm season (from June through Oct.) of 1976-1981. This period was chosen based on analysis availability. The NMC analyses were saved at National Hurricane Center from 1976-1984 and FNOC analysis data were archived starting in 1973.

Individual cases were selected when the maximum wind speed was greater than or equal to 35 knots at synoptic time $(0000$ or 1200 GMT). For each case, two analyses and the same storm data were used in making a $72 \mathrm{~h}$ SANBAR forecast. The initial deep-layer wird fields for SANBAR were derived from 1000, 700, 400 and $250 \mathrm{hPa}$ for NMC analyses and were derived from surface, 700,400 and $250 \mathrm{hPa}$ for FNOC analyses. The values of SANBAR Mercator grid system were interpolated from the NMC Northern Hemisphere grid system on polar stereographic projection and from FNOC Mercator global band grid system. For each case two sets of forecast were made and the forecast errors were calculated using best track positions. These post season best tracks are derived from all available data. The total numbers of cases evaluated were 432, 404, $360,311,260,219$ for the prediction intervals $12 \mathrm{~h}, 24 \mathrm{~h}, \cdots 72 \mathrm{~h}$, respectively.

Table 1, which gives the two sets of average errors for all cases and the average value of the distances between two forecast positions from NMC and FNOC analyses (DIF), indicates that except $12 \mathrm{~h}$ forecast, the DIF for every prediction interval is bigger than half the forecast errors. We also see that the errors from the NMC analyses are smaller at every prediction interval. We also examined the right angle error (RIAN), which is defined as the magnitude of perendicular distance of the forecast position from the verifying track, and find the FNOC forecast somewhat better at 48,60 and $72 \mathrm{~h}$.

Stratification of the errors by motion direction, initial position, intensity etc. gives nearly the same results as the comparison for all cases.

The zonal and meridional biases of the

Table 1 The comparison of average errors (n. m.) for all cases. GCD is the great circle distance error. RIAN is the right angle error. DIF means the average GCD difference between two forecasts from NMC and FNOC (in unit n.m.).

\begin{tabular}{|c|c|c|c|c|c|c|c|c|c|c|c|c|}
\hline & \multicolumn{2}{|c|}{$12 \mathrm{hr}$} & \multicolumn{2}{|c|}{$24 \mathrm{hr}$} & \multicolumn{2}{|c|}{$36 \mathrm{hr}$} & \multicolumn{2}{|c|}{$48 \mathrm{hr}$} & \multicolumn{2}{|c|}{$60 \mathrm{hr}$} & \multicolumn{2}{|c|}{$72 \mathrm{hr}$} \\
\hline & $\mathrm{GCD}$ & RIAN & GCD & RIAN & GCD & RIAN & GCD & RIAN & CGD & RIAN & CGD & RIAN \\
\hline $\mathrm{NMC}$ & 30.0 & 19.0 & 61.9 & 40.0 & 110.7 & 70.0 & 169.0 & 102.8 & 237.8 & 137.4 & 307.2 & 171.8 \\
\hline FNOC & 32.0 & 20.0 & 71.6 & 41.1 & 135.6 & 70.3 & 212.0 & 100.9 & 299.9 & 132.1 & 389.3 & 161.2 \\
\hline DIF & \multicolumn{2}{|c|}{9.3} & \multicolumn{2}{|c|}{32.1} & \multicolumn{2}{|c|}{69.5} & \multicolumn{2}{|c|}{$115: 3$} & \multicolumn{2}{|c|}{163.1} & \multicolumn{2}{|c|}{213.7} \\
\hline Cases & \multicolumn{2}{|c|}{432} & \multicolumn{2}{|c|}{404} & \multicolumn{2}{|c|}{360} & \multicolumn{2}{|c|}{311} & \multicolumn{2}{|c|}{260} & \multicolumn{2}{|c|}{219} \\
\hline
\end{tabular}


Table 2 The zonal and meridional biases of storm motion perdictions (in unit n.m.). The positive values represent westward distance for zonal motion and northward distance for meridional motion.

\begin{tabular}{llrrrrrr}
\hline & $12 \mathrm{hr}$ & $24 \mathrm{hr}$ & $36 \mathrm{hr}$ & $48 \mathrm{hr}$ & $60 \mathrm{hr}$ & $72 \mathrm{hr}$ \\
\hline \multirow{2}{*}{ NMC } & Meridional biases & 8.3 & 14.5 & 33.1 & 62.7 & 106.7 & 154.3 \\
& Zonal biases & -0.3 & 3.3 & 7.0 & 2.8 & -8.7 & -31.9 \\
\multirow{2}{*}{ FNOC } & Meridional biases & 11.2 & 27.7 & 63.6 & 112.9 & 116.6 & 215.4 \\
& Zonal biases & -0.7 & -6.4 & -23.0 & -55.2 & -103.7 & -159.7 \\
\hline
\end{tabular}

forecasts come from the average of the zonal and meridional prediction errors as shown in Table 2. We find bigger zonal and meridional biases of using FNOC analysis. Alternatively we estimated the forecast biases using the along track and the across track system of Shapiro and Neumann (1984). The results

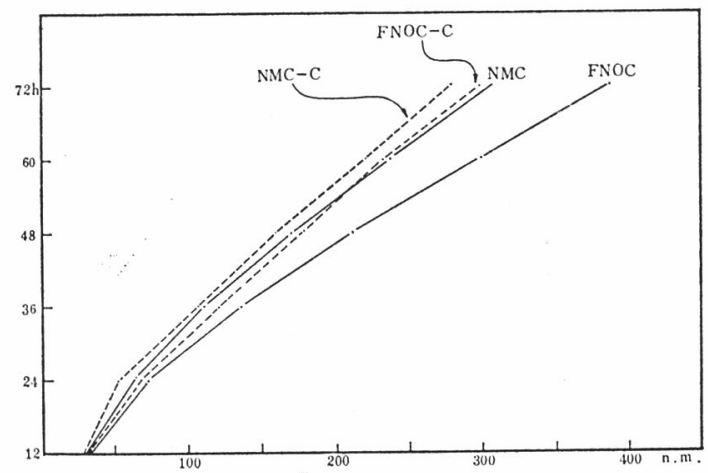

Fig. 2 The original average errors and the errors after bias corrections (NMC-C, FNOC-C) of using NMC and FNOC analyses.

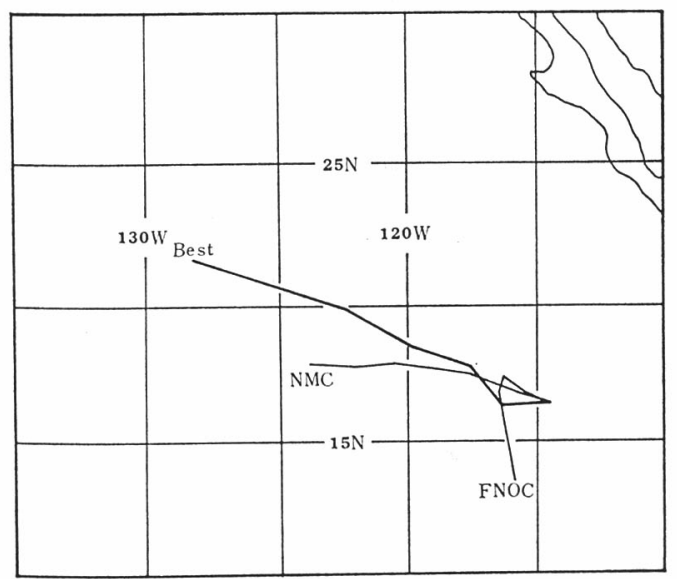

Fig. 3 The forecasts for storm GILMA on July 17, 1978 at 0000 GMT

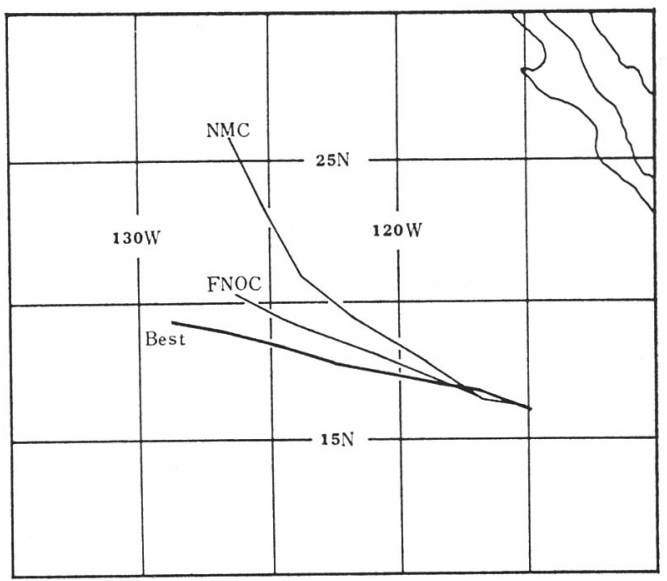

Fig. 4 The forecasts for storm DORA on July 13, 1981 at 1200 GMT.

are nearly the same as the results from zonal and meridional biases.

Fig. 2 shows the original errors and the errors after the biases were removed from the predictions.

It is interesting to note the magnitude of error when different analyses are used as the initial fields, particularity with regard to biases. The forecast tracks with greatest differences between NMC and FNOC analyses are shown in Fig. 3 and Fig. 4.

Fig. 3 gives the forecasts for storm GILMA on July 17, 1978 at 0000 GMT. It shows that NMC is superior to that at FNOC. The forecasts for storm DORA on July 13, 1981 at 1200 GMT are in Fig. 4 which shows that FNOC is superior to that at NMC.

\section{Summary and conclusions}

Two kinds of analysis methods were tested in a numerical tropical cyclone model over the easten North Pacific area during 1976- 
1981 warm seasons. We found that the NMC spectral analyses gave generally superior forecasts than the tropical analyses of FNOC when they were used for the initial fields of the SANBAR numerical tropical cyclone model.

The different initial fields significantly affected model skill in terms of mean forecast error and biases. This study demonstrated the importance of the large-scale analysis in tropical cyclone prediciion and suggests that more effort be made in the analysis in order to have better numerical prediction especially for the short-range forecasts.

\section{Acknowledgements}

The authors wish to thank M. Fiorino at Fleet Numerical Oceanography Center for providing the Navy analysis data that made this study possible, and A. Desmarais of NMC for his great help.

\section{References}

Bergman, K., R. Mcpherson and J. Newell, 1974: A description of the Flattery global analysis method No. 1. National Weather Service Technical Procedures Bulletin No. 105. Silver Spring, Maryland.

Fiorino, M., 1985: A brief deseription of the Navy tropical analysis and the NOGAPS analysis.
Appendix E of NAVENVPREDRSCHFAC Tech. $R E P$. TR 85-03, NEPRF Monterly CA 93943, $152 \mathrm{pp}$.

Flattery, T., 1970: Spectral modls for global analysis and forecasting. Proceedings of the 6th AWS technical exchange conferende, U.S. Navy Academy, Air Weather Service Technical Report 242.

Leftwich, P., C. Nenmann and H. Friedman, 1977 : Characteristics of the NMC spectral analysis in tropical regions of the western hemisphere. Proceedings of the 11 th AMS conferences on Hurricanes and Tropical Meteorology. American Meteorological Society. 478-483.

Mathur, M., 1978: A case study of analyses and forecasts over the tropics with NMC operational models. NMC Office Note, No. 187.

Numann, C., 1979: A guide to Atlantic and Eastern Pacific models for the prediction of tropical cyclone motions. NOAA Tech. Memo. NWSNHC-11.

Pike, A., 1972: Improved barotropic hurricane track prediction by adjustment of the initial wind field. NOAA Tech. Memo. NWS-SR-66.

Sanders, F. and R. Burpee, 1968: Experiments in hurricane track forecasting. J. Appl. Meteor., 7, 313-323.

-, A. Pike and J. Gaertner, 1975: A barotropic model for operational prediction of tracks of tropical storms. J. Appl. Meteor., 14, 265280.

Shapiro, L. T. and C. J. Neumann, 1984: On the structure and orientation of grid systems for the statistical prediction of tropical cyclone motion. Mo. Wea. Rev., 112, 188-199. 